حكم العمل في المصارف الربوية

إعداد

د. محمد بن علي بن إبراهيم آل فائع

- 1805 - 
- 1806 - 


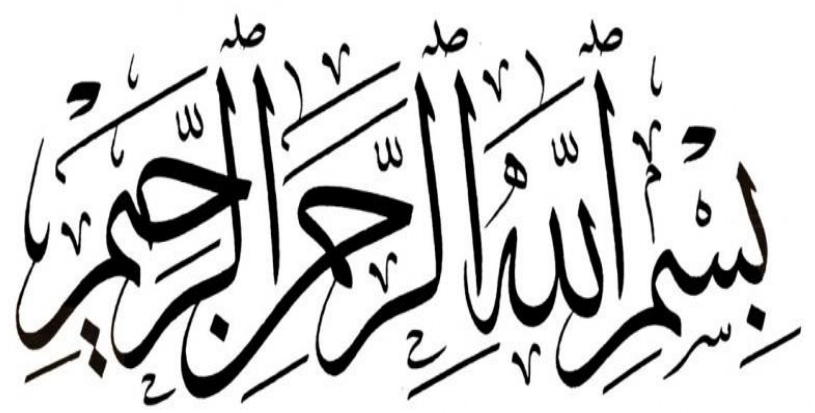

- 1807 - 


\section{المقدمة}

إن الحمـد الله نحمده ونسـتعينه ، ونعوذ بـالله مـن شـرور أنفسـنا ، ومن سيئات أعمالنا ، من يهده الله فلا مضل له ، ومن يضلل فلا هـادي لله ، وأشـه ألا إله إلا الله وحده لا شريك لـه ، وأشـهـ أن محمدا عبده ورسوله.

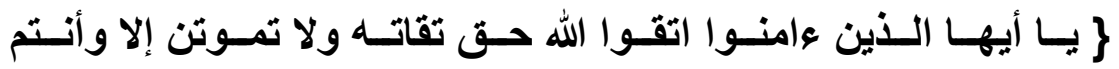
مسلمون\{[ آل عمران : 102]\} يـا أيها النـاس اتقوا ربكم الذي خلقكم من نفس واحدة وخلق منها زوجها وبـ منهمسا رجـالا كثيرا ونسـاء

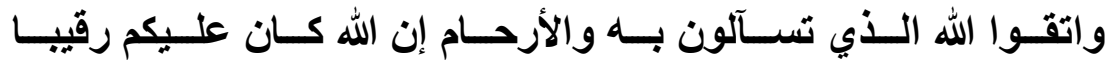

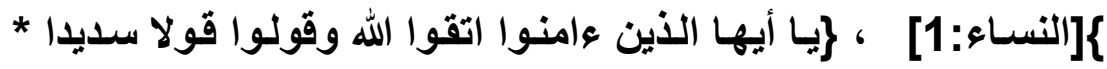
يصلح لكم أعمـالكم ويغفر لكم ذنـوبكم ومن يطع الله ورسوله فقد فـاز [70: فوزا عظيمائ الأحزاب أما بعد : (1) n

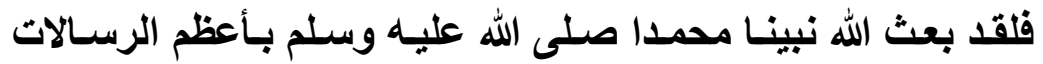
وخاتم الديانات ، فلما كان هذا الدين العظيم هو خـاتم الديانات اقتضت

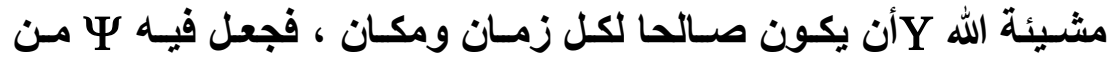
أسباب البقاء ، ومقومات الخلود ، وموجبات التعايش مع كافة الظروف باختلاف الأزمنة والأمكنة ما يجعله دينا باقيـا ، ورسـالة خالدة إلى يوم القيامـة ، فيتحقق وعد الله سبحانه بإظهـاره على الدين كله ولـو كره الكافرون ، وإنه كلما تقادمت الأزمنة ، وتجددت العصور ظهر في حياة النـاس مـا يسـتوجب معرفتهم لحكمـه في شـرع الله ، ليعبـد الله على بصيرة ، ويكون النـاس على نور من ربهم ، وإن ممـا ظهرت الحاجة

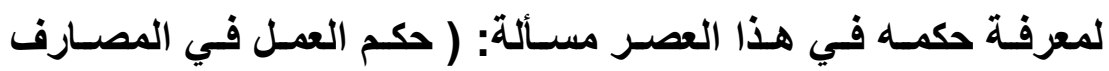
الريويـة ) فلا يخفى على مسلم مـا لأهمية الكسب الحلال وخطورتـه ؛ 
فبه تزكو النفوس الطيبة ، وتصفو القلوب الصـالحة ، وتتبت الأجساد الطـاهرة ، وتستجاب اللدعوات الصـادقة ؛ لذا فقد حرص المؤمنسون الراجون لقاء ربهم في انتقاء الدرهم الحلال ، والبعد عن الحرام ، ولمـا

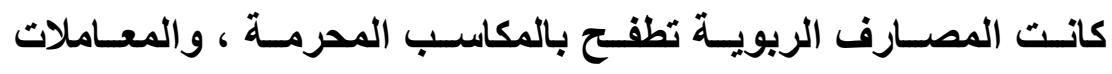

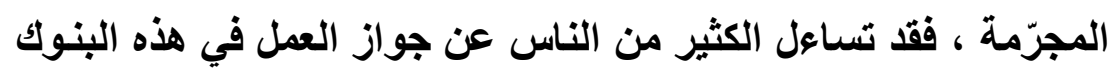

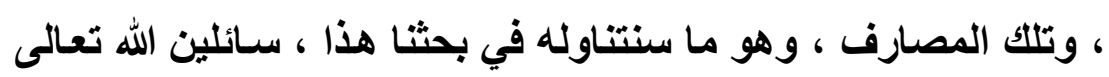

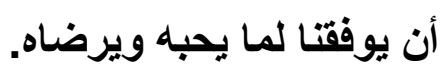

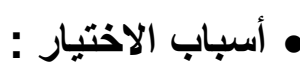

أولا : لم أجد فيم أعلم أن هذا الموضوع أفرد في رسـالة علمية أو بحثا علميا محكما. ثانيا : حاجة الناس إلى معرفة الحكم في مثل هذه المسألة.

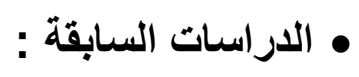

لا أعلم حسب بحثي أن هذا الموضوع أفرد في رسـالة علميـة أو بحثا علميا محكما .

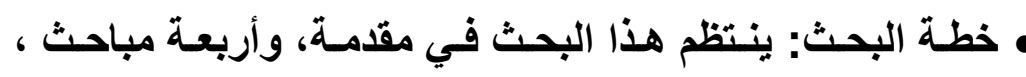
وخاتمة، وفهرس للموضوعات وآخر للمراجع ، على النحو التالي:

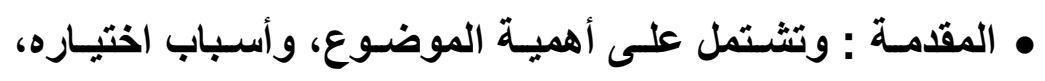
و الاراسات السابقة، وخطة بحثثه، ومنهجه.

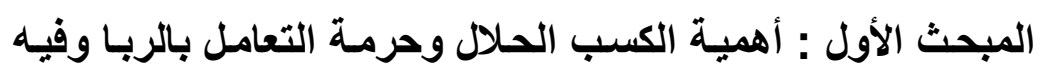

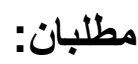

المطلب الأول : أهمية الكسب الحلال . المطلب الثاني : حرمة الربا . 
المبحث الثاني : حكم العمل في المصارف الربوية بأعمال الربا . المبحث الثالث : حكم الاستئجار على حمل الخمر.

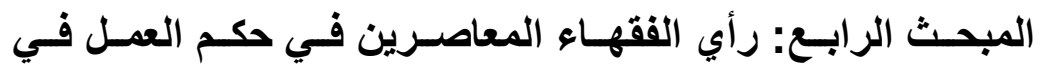

$$
\text { المصارف الربوية بغير أعمال الربا . }
$$

الخاتمة : وبينت فيها ما توصلت إليه من نتائج. الفهارس : قتت بوضع فهرس للمراجع وآخر للموضوعات منهج البحث: سرت في دراسة مسائل هذا البحث، وفق الآتي: أولاً: عنونت للمسألتين بعنوان مناسب. ثنانياً: قمت بييان صورة كل مسألة بذكر تمهيد يوضحها. ثالثاً: اتبعت في تناول المسائل الفقهية ما يلي:

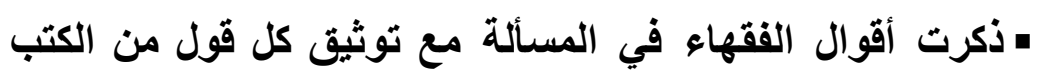
المعتبرة للمذهب المنسوب إليه.

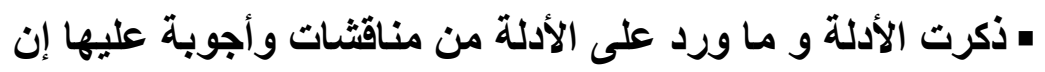

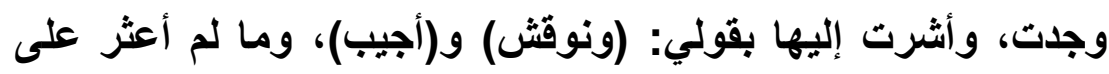

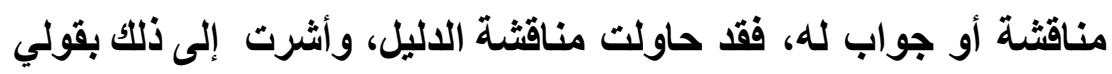
(ويمكن أن يناقش) و(ويمكن أن يجاب). • رجحت بين الأقوال الفقهية وما توصلت إليه من حكم في هذه المسألة مع بيان سبب الترجيح. 


$$
\text { •رابعاً: التوثيـــق: }
$$

1. عزوت الآيات القرآنية بذكر اسم السورة، ورقم الآية، وكتابتها

$$
\text { بالرسم العثماني. }
$$

2. خرجت الأحاديث، فإن كان الحديث في الصحيحين أو أحدهما فقد اكتفيت بذلك، وإن كان في غيرهما فقد قمت بتخريجه من بقية كتب السنة مبيناً درجته من أقوال أهل العلم المعتبرين. 3. عزوت الآثار الواردة في صلب البحث عن الصحابة إلى مصادرها الأصلية، إلا ما قد يتعذر العثور عليه. 4. ترجمت للأعلام الوارد ذكرهم في البحث. 5. بينت معنى المصطلحات العلمية والألفاظ الغريبة. خامسا: التزمت بعلامات الترقيم، وضبط ما يحتاج إلى ضبط. سادسا: ذيلت البحث بالقهارس المشار إليها في ذيل خطة البحث. والله أسأل أن يوفقنا لما يحب من القول والعمل ، وأن يعصمنا من الزلل ، وأن يجعل عملنا خالصا لوجه ، وابتغاء مرضاته ، إنه ولي ذلك والقـادر عليها ، وصلى الله وسـلم على نبينـا محمد وعلى آله وصـبه أجمعين. 


\section{المبحث الأول}

أهمية الكسب الحلال وحرمة التعامل بالربا

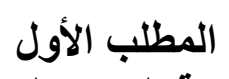

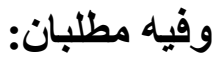

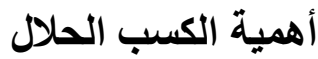

لقد حث الثـارع الكريم على الكسب الحلال وأوجبه ، وحذر من

الكسب الحرام وحرمـه. قـال تعالى : \} وكلوا ممـا رزقكم الله حللا طيبا

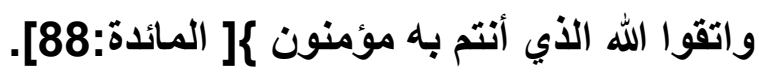

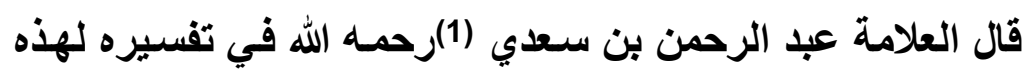

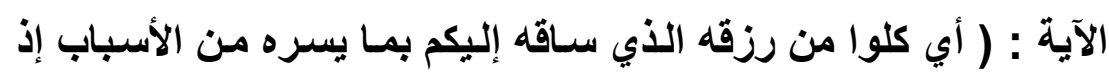

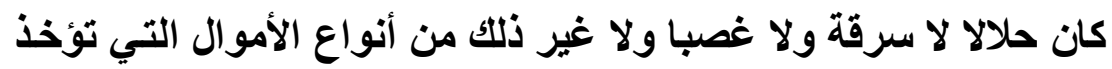
بغير حق وكان أيضا طيبا وهو الذي لا خبث فيه فخرج بذلك الخبيث من السباع والخبائث ) و اتقوا الله ( في امتثال أوامره واجتناب نواهي لأهيه)

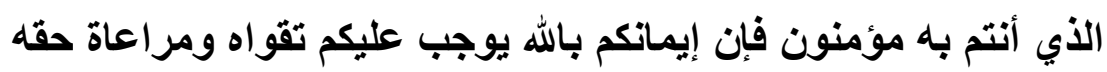

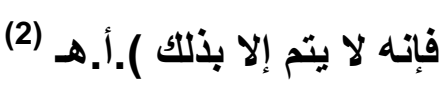

هو: عبد الرحمن بن ناصر بن عبد الله السعدي التميمي: مفسر، من علماء

الحنابلة، من أهل نجد، مولده سنة: (1307هـ) ووفاته (1376هـ) في غنيزة

(بالقصيم) وهو أول من أنثأ مكتبة فيها (سنة 1358) له نحو 30 كتابا، منها

الكتب المطبوعة الآتية: (تيسير الكريم المنان في تفسير القرآن). انظر ترجمته

في: الأعلام للزركلي (340/3) مشاهير علماء نجد وغيرهم (50/3) المعجم

الجامع في تراجم العلماء وطلبة العلم المعاصرين (152/1).

(242/1) انظر تفسير الكريم الرحمن (24). 
و عن أبي هُرَيْرَةً (1) رضي الله عنه قال : قال رسول الله صلى الله

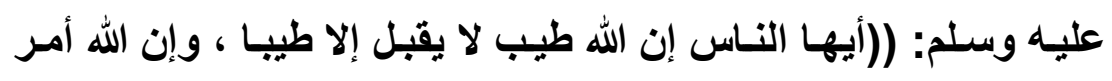

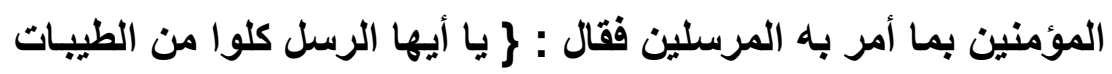

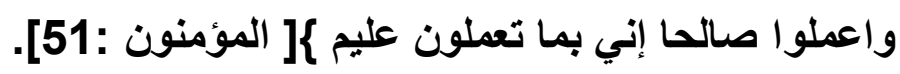

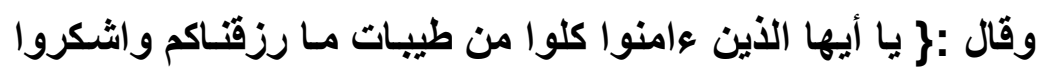

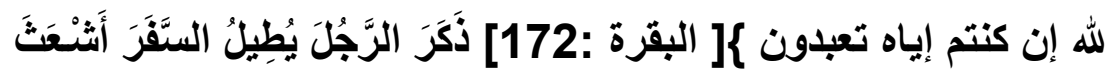

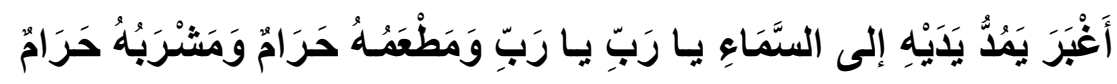

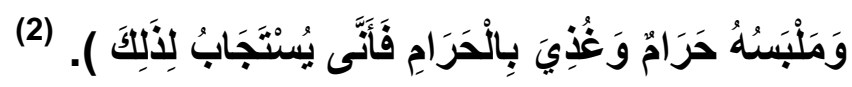

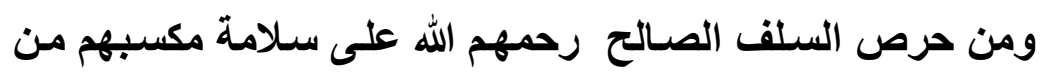

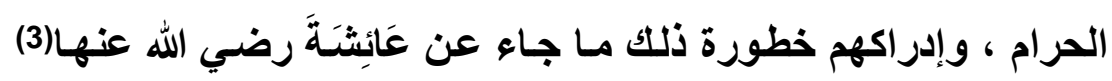

(1) هو الصحابي الجليل عبدالرحمن بن صخر الاوسي، مشهور بكنيته، صاحب رسول الله م، اختلف في اسمه، واسم أبيه، لكن هذا أصح، أسلم عام خيير، لزم رسول الله م، وكان من أحفظ الصحابة، مات سنة (57هـ)(نظر: الإصابة (316/4)، الاستيعاب (850-852). (2) أخرجه مسلم ، كتاب الزكاة ، باب قبول الصدقة من الكسب الطيب وتربيتها ، 703/2 ، حديث رقم .(1015)

(3) عائشة بنت أبي بكر الصديق التيمية أم المؤمنين تكنى أم عبد الله الفقيهةو أمها أم رومـان بنت عامر بن عويمر بن عبد شمس بن عتاب بن اذينه بن سبيع بن دهمان بن الحارث بن غنم بن مالك بن كنانه وقيل غير ذلك في نسبها. وفضل عائشة على النساء كفضل الثريد علي سائر الطعام ومناقجها وفضانلها كثيرة جدا ذكر غير واحد من أهل العلم أن التبي م مات وهي بنت ثماني عشرة سنة، توفيت في رمضان سنة (58هـ وقيل 57هـ) انظر ترجمتها في: الإصابة (16/8)طبقات ابن سعد (58/8)أسد الغابة (205/7). 


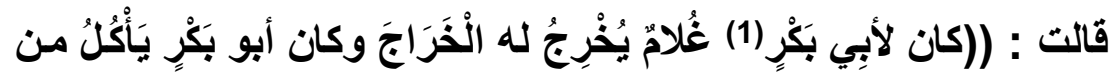

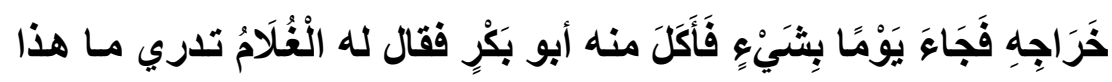

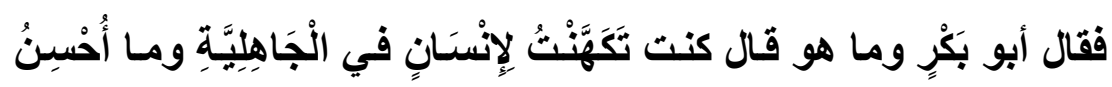

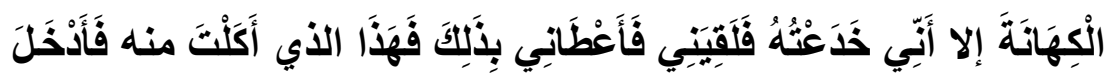

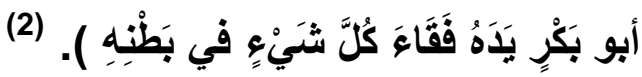

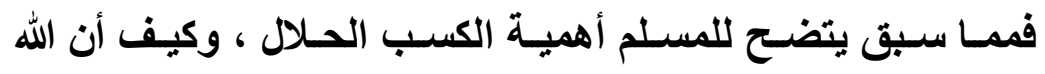
تعالى أمر به ، ورتب عليه إجابة الدعاء ، وانها لا يقبل تعالى إلا طيبا

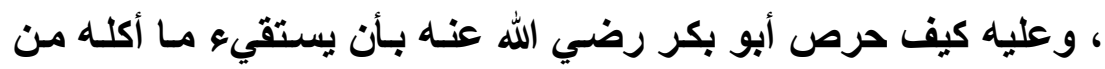
الحرام ، ما ذالك إلا لعظيم إثم المكسب الحرام كمـا علم الصديق رضي رئي

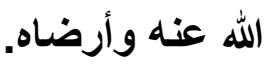

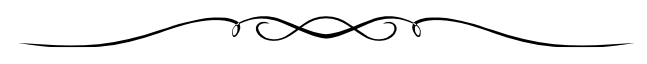

أبو بكر الصديق هو: عبالله بن عثمان بن عامر القرشي التمييمي، ابن أبي

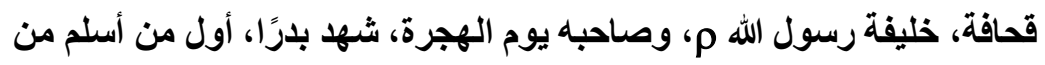
الرجال، بويع يوم سقيفة بني ساعدة، وهو أفضل الصحابة، مات سنة (13هـ). انظر: الإصابة (169/4)، الاستيعاب ص(429-435).

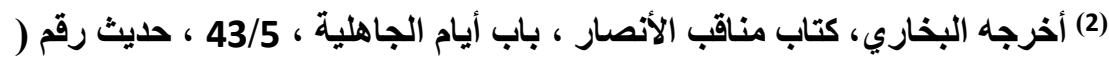




\title{
المطلب الثاني
}

\author{
حرمة الربا
}

لقد جاعت نصوص الثريعة الإسلامية محذرة من التعامل بالربـا ، ومرتبة على التعامل به الوعيد الثديد ، منها ما هو في القرآن العظيم ، ومنها ما جاء على لسان النبي الكريم ، عليه أفضل الصـلاة ، وأزكى التسليم ، فأما الأدلة على تحريم الربا من القرآن فمنها: قول الله تعالى \} الذين يأكلون الريوا لا يقومون إلا كما يقوم الذي يتخبطه الشيطان من المس ذلك بأنهم قالوا إنما البيع مثل الربوا وأحل الله البيع وحرم الربوا فمن جاءه موعظة من ربـه فانتهى فله مـا سـلف وأمره إلى الله ومن عاد فأولئك أصحاب النار هم فيها خالدون \{]البقرة 275 :

مضاعفة واتقوا الله لعلكم تفلحون \{[ آل عمران : 130 ]. وأما من السنة : أ ـ عن جـابر(1) قـال: (لعن رسـول الله صلى الله عليهه وسـلم آكل

الربا، وموكله، وكاتبه، وشاهديه. وقال: هم سواء)) (2)

جابر بن عبد الله بن عمر بن حرام. أنصساري، سلمي. صحابي؛ ولد قبل الهجرة بستة عثرسنة، شهد بيعة العقبة. وغزا مع النبي • 19 غزوة. أحد المكثرين من الرواية عن النبي •، وكانت له في أواخر أيامه حلقة بالمسجد النبوي ويؤخذ عنه فيها العلم. كف بصره قبل موتهه بالمدينة سنة: (78هـ). ح. انظر ترجمته في: الإصابة (434/1)الاستيعاب (219/1) أسد الغابة (377/1). (2) أخرجه مسلم ، باب لعن آكل الربا وموكله، 1219/3، حديث رقم ( 1598 ). 
ب - عن سمرة بن جندب(1) رضي الله عنه قال: قال النبي صلى الله عليه وسلم: (ارايت الليلة رجلين أتياني فأخرجاني إلى أرض مقدسة فانطلقتا حتى أتينا على نهر من دم، فيه رجل قائم وعلى وسط النهر،

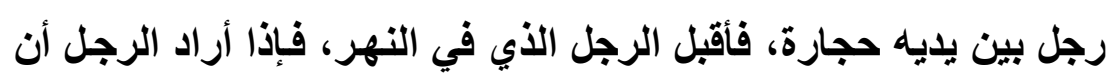

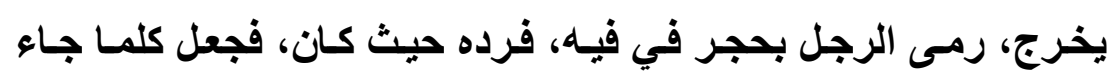

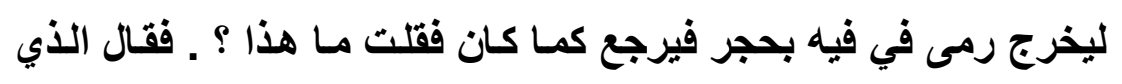

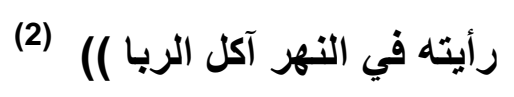

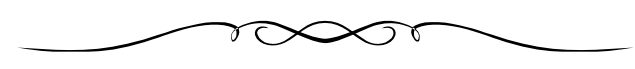

هو سمرة بن جندب بن هلال بن جريح الفزاري. صحابي، من الثجعان القادة. نشأ في المدينة ونزل البصرة. فكان زياد يستخلفه عليها إذا سـار إلى الكوفة. روى عن النبي م وعن أبي عبيدة. وعنه ابنـاه سليمان وسـد، وعبد الله بن

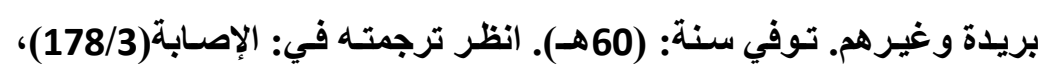

$$
\text { وتهذيب التهذيب(207/4) الثقات (174/3). }
$$

(2) أخرجه البخاري ، باب آكل الربا وشاهده وكاتبه ، 59/3 ، حديث رقم (2085). 


\section{المبحث الثاني}

حكم العمل في المصارف الربوية بأعمال الربا

إنّ العمل في الربا في المصرف الربوي، أو في غيره، هو عمل المدل

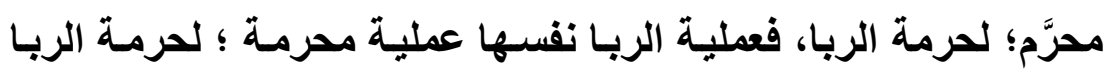

ذاته ؛ وللنص المحرم هذا العمل فمن أكل الربا، أو أطعمـه غيره، أو أو الريا

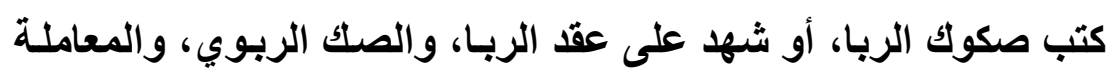

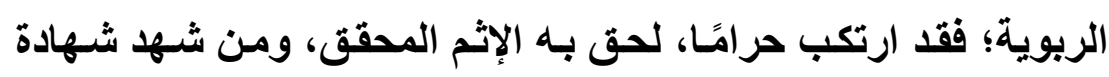

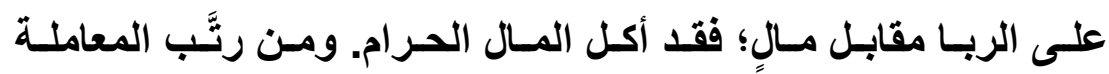
الربوية، وكتب صكها، وأخذ أجرة على ذلك؛ فقد أكل المال الحرام. فعن جابر رضسي الله عنه قـال: ((لعن رسول الله صلى الله عليه

وسلم آكل الربـا، وموكلـه، وكاتبه، وشـاهديه. وقـال: هم سواء)) (1). واللعن يقتضي التحريم وهذا الحكم محل اتفاق بين العلماء، فالنص صريح واضح جليّ، لا لألئ يحتمل التاويل، ولا اجتهاد في مورد النص (2) ، بل إن العمل في هذه البنوك في أعمال الربا لا شكك أنه من قبيل التعاون على التى الإثم والعدوان

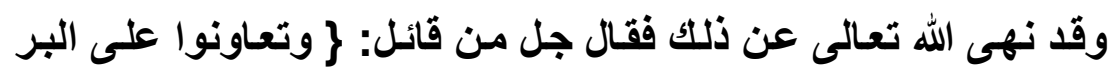

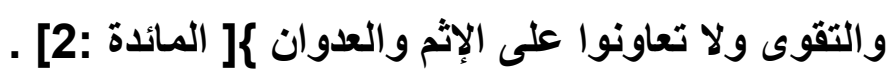

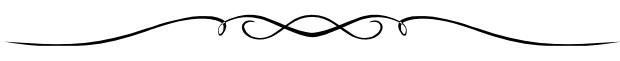

(1) سبق تخريجه ص10.

(2) انظر رسالة العطل في المصارف الريوية لحمد أحد حسين ، ص 7 ، موقع الفقة الإسلاهي. 


\section{المبحث الثالث}

\section{حكم الاستئجار على حمل الخمر}

إن من المعلوم شرعا أن الإعانـة على الإثم و العدوان ممـا حرمـــ

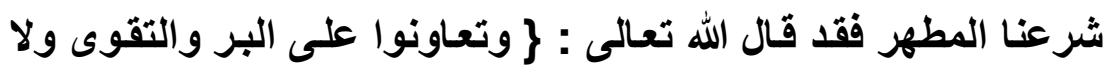

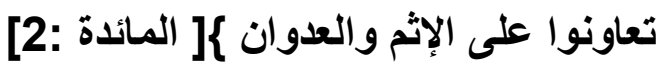

فإذا علم ذلك فهل عمل العامل في البنوك الريوية في غير أعمال

الربا يعتبر من قبيل الإعانة على المعصية أم لا ؟

يمكن أن نخرج هذه المسألة على اختلاف الفقهاء رحمهم الله في الاعله

حكم الاستئجار على حمل الخمر.

• حكم الاستئجار على حمل الخمر.

اختلف الفقهاء رحمهم الله في حكم الاستنجار على حمل الخمر

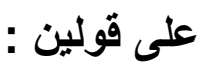

القول الأول: المنع وهو قول الجمهور. (1)

القول الثاني : الجواز ، وهو قول أبي حنيفة. (2)

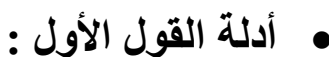

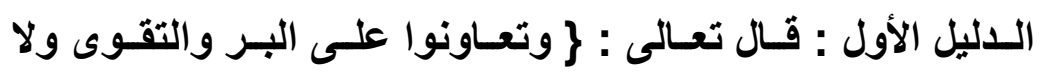

[2: تعاونوا على الإثم و العدوان [ [المائدة

* وجه الدلالة : أن حمل الخمر معصية ؛ لكونه إعانة على المعصية (1)

1(1) انظر الددونة لمالك 436/3 ، مواهب الجليل 409/5 ، التنبيه 123/1 ، مغتي

المحتـاج للظطيب الثشرييني 449/3 ، المغتي لابن قدامسة 407/5 ، الثـرح

الكبير على المقنع 29/6.

(2) انظر المبسوط ، بائع الصنائع 190/4 ، الهاية 378/4. 
ورالإعانة على المعصية من التعاون على الإثم والعدوان الذي

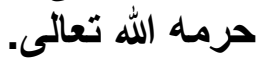

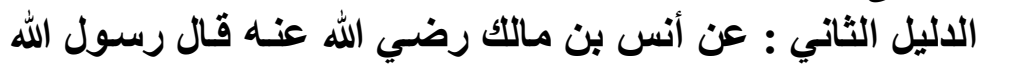

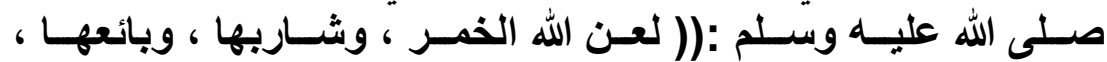

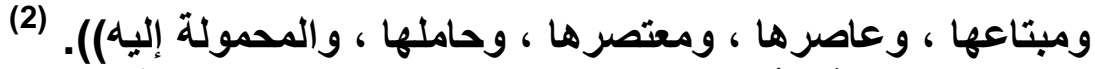

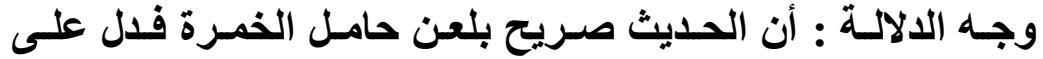
تحريم الاستئجار لحملها. * نوقش : الحديث محمول على الحمل المقرون بقصد المعصية

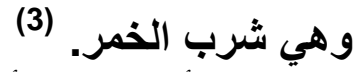

يمكن أن يجاب : أن حملها في الغالب إنما يكون لأجل شربها.

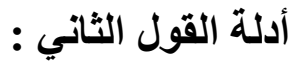
• • اللاليل الأول : أن نفس الحمل ليس بمعصية بدليل أن حملها

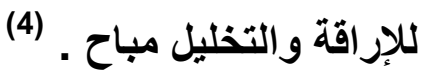
• الدليل الثاني : أن العمل لا يتعين عليه بدليل أنـه لو حمله مثله

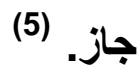

• نوقش : أن هذا يبطل باستجار أرض ليتخذها مسجدا. (6) • الدليل الثالث : القياس على عصر العنب وقطفه ، ووجه ذلك : أن حمل الخمر ليس سببا للمعصية وهو شرب الخمر ؛ لأن ذلك يحصل 1) (190/4 انظر بائع الصنائع (2) أخرجه أبو داود ، كتاب الأثربة ، باب العب يعصر للخمر ، 326/3 ، حديث رقم (3674) ، والترمذي ، باب النهي أن يتذذ الخمر خلا ، 581/3 ، حديث رقم (1295) ، وصححه الألباني في إرواء الغليل 50/8. (3) انظر بائع الصنائع 190/4 ، الهاية للمرغيناني 379/4.

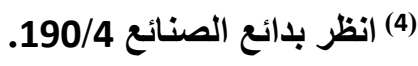
(5) - انظر المغني لابن قدامة 407/5.

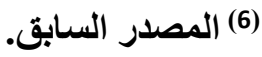


بفعل فاعل مختـار ، وليس الحمل من ضرورات الشرب فكانت سببا

محضا فلا حكم لله كعصر العنب وقطفه. (1)

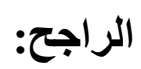

الراجح والله أعلم هو قول الجمهور بتحريم الاستئجار بحمل الخمر

$$
\text { لما يلي : }
$$

أولا: قوة أدلتهم .

ثانيا : أن القول بالمنع فيه براءة للأمة ، واتقاء للشبهة.

(1) انظر بدائع الصنائع 190/4 ، الهداية للمرغيناني 379/4. 


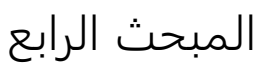

حكم العمل في المصارف الربوية بغير أعمال الربا

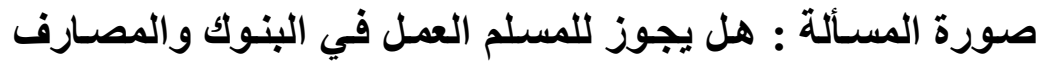
الربوية في غير أعمال الربا كالحراسة مثلا أم لا؟

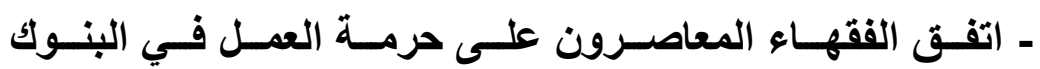
و المصارف الربوية بأعمال الربا ولا أعلم أحدا أفتى بجواز ذلك والعياذ

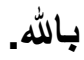

و إنمـا اختلفوا في حكم العمل في المصـارف الربويـة بغير أعمـال

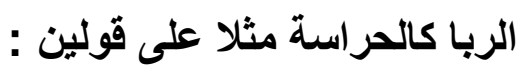

القول الأول : حرمة العمل في المصارف الربوية مطلقا ، وهو مـا

ذهب إليه الإمامان عبد العزيز بن باز (1)

الله

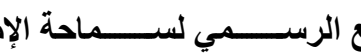
(1) htt://www.binbaz.org.sa/fatawa/4035 حيث سأل سائل الشيخ عبد العزيز بن باز رحمه الله قائلا : قدمت إلى هذه الديار الطيبة منذ أكثر من خمس سنوات ، لقد عانيت وتعبت غاية التعب أول الأمر، ولم يكن عند كفيلي أي عمل يخرجني مما أنا فيه من ضيق وحاجة للمال؛ لتسير به حياتي، وأنفق على أهل بيتي من الوالدين والإخوان ، وبحثت عن عمل، وتنقلت في أكثر من أربع مؤسسـات تجاريـة، وأخيراً استقر بي المقام في أحد المصارف هنا في الرياض، وقد بذلت غاية جهدي ، وأخلصت في عملي حتى صرت محاسباً في الحسابات الجارية ، فعلمت أن هذا المصرف يضع أكثر ماله في بنوك داخل المملكة وخارجها بالفائدة الربويـة ، وهنـاك حسـابات للعملاء تأتينـا الأوراق المصرفية بتسجيل فائدة ربوية لحساباتهم طرفنا، وهي من بنوك خارجية ، ويعلم الله تعالى أني في غاية الضيق لهذا الأمر، ولم يهـأ لـي بـال منذ أن عرفت هذا 
الأمر ، علماً بأني قد تزوجت وأحضرت زوجتي، ورزقني الله تعالى بولدين، وأنا طالب علم شرعي".. إلى أن قال: "أنا أحب الفقه في الدين، وأحضر ندوات العلم، وسوف أقع في ضيق وفي حرج لو تركت هذا العمل، وسأتأخر في الصرف على أبي وأمي، فبالي مشغول من ذلك، و أنتظر من سماحتكم فتوى بهذا.ا. فأجاب سماحته رحمه الله بقوله : ( الله جل وعلا أحل لعباده مـا فيها نجاتهم وقضـاء حاجاتهم، وحرم عليهم ما يضر هم؛ فليس العبد مضطراً إلى مـا حرم الله عليه، بل عليه أن يسعى جهده في طلب الرزق الحلال ، والتوظف في البنوك لا يجوز؛ لأنه إعانـة لهم على الإثم والعدوان ـ سواء كان محاسباً أو كاتباً أو غير ذلك ـ فالواجب على المؤمن أن يحذر

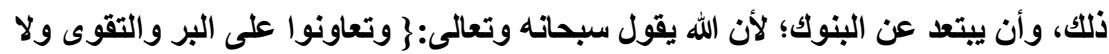
[2: تعاونوا على الإثم و العدوان واتقوا الله إن الله شديد العقاب\{] المائدة ] فالتعاون مع البنوك أو مع قطاع الطريق أو مع السراق، أو مع الفثاشين، أو مع أصحاب الرشوة، كله تعاون على الإثم والعدوان، فلا يجوز ، ومـا قبضته قبل ذلك ـ أي قبل العلم ـ فلك ما سلف، وما كان بعد العلم فليس لكك؛ لقول الله جل وعلا: \} فمن جاءه موعظة من ربه فاتتهى فله ما سلف وأمره إلى الله ومن عاد فأولئك أصحاب النار هم فيها خالدون \{[البقرة : 275] فما قبضته سـابقاً قبل أن تعلم فهو لك، وأمسا بعد أن علمت، فعليك أن تترك هذا العمل، وأن تتوب إلى الله سبحانه ممـا سلف، وتبذل مـا قبضته من طريق الربا وأنت عالم بـه في جهة البر والخير؛ كالصدقة على الفقراء والمساكين، إلى غير ذلك، حتى تتخلص من هذا المال الذي جاءك بغير وجه شرعي ، وقد صح عن رسول الله عليه الصلاة والسلام: (أنه لعن آكل الربا وموكله، وكاتبه،

$$
\text { وشاهديه، وقال: ((هم سواء)).أ.هـ. }
$$


ومحمد بن عثيمين (1) رحمهما الله .

وهي أيضا فتوى اللجنة الدائمة (2).

http://binothaimeen (1) انظر الموقع الرسمي لفضيلة الثبخ محمد بن صسالح بن عثيمين

http://binothaimeen

حيث سئل رحمـه الله مـا حكم العمل في البنوك الربويـة ومعاملتها؟ فأجـاب رحمـه الله : العمل فيها محرم لأنها إما إعانة على الربا، فإذا كان إعانة على الربا فإنـه يكون داخلاً في لعنة المعين، حيث صح عن النبي ? 》أنه لعن آكل الربا، وموكله، وشاهديه، وكاتبه، وقال هم سواء《) ، وإن لم يكن إعانة فهو رضـا بهذا العمل، وإقرارٌ لـه، ولا يجوز التوظف في البنوك التي تتعامل بالربا.كمـا سئل رحمـه الله : هل يجوز العمل في مؤسسة ربويـة كسـائق أو حارس ؟ فأجساب رحمه الله : لا يجوز العمل بالمؤسسات الربوية، ولو كان الإسـان سـائقاً أو حارسـاً وذلك لأن لدوله في وظيفة عند مؤسسـات ربويـة يستلزم الرضـا بها لأن من ينكر الثـء لا يمكن أن يعمل لمصلحته ، فإذا عمل لمصلحته فإنه يكون راضياً به، والراضي بالثيء المحرم يناله من

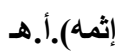

(2) حيث جاء في فتوا اهم رقم 2608 على سؤال نصه : هل يجوز للإنسان العمل في بنك يتعامل بالربا مع أنه لا يقوم في البنك بعمل ربوي ولكن دخل البنـك الكلي ربـا ؟ فأجابت اللجنـة الدائمـة بمـا نصه : لا يجوز لمسلم أن يعمل في بنك تعامله بالربا ، ولو كان العمل الذي يتولاه ذلك المسلم في البنك غير ربوي لتوفيره لموظفيه الذين يعملون في الربويات ما يحتاجونه ويستعينون بـه 2: على أعمالهم الريوية ، وقد قال تعالى : \} ولا تعاونوا على الإثم والعدوان \{] المائدة اللجنة الدائمة للبحوث العلمية والإفتاء عضو عبد الله بن قعود عضو عبد الله بن غديان نائب رئيس اللجنة عبد الرزاق عفيفي الرئيس عبد العزيز بن باز http://www.alifta.net/fatawa/fatawaDetails.aspx?View=Page\&PagelD=54 
القول الثاني : جواز العمل في المصـارف الربويـة فيمسا ليس مـن أعمال الربا وذهب لهذا لجنة الإفتاء الأردنية (1)و الشيخ عبد

(2)

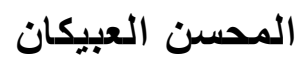

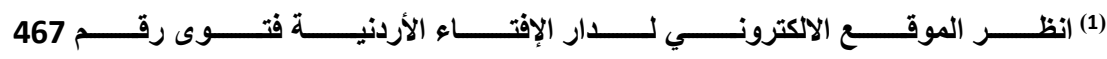
http://www.aliftaa.jo/question.aspx

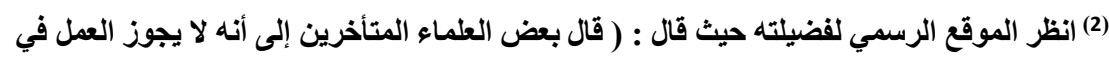

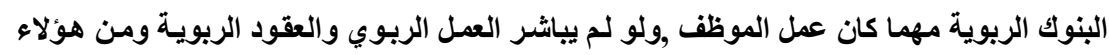

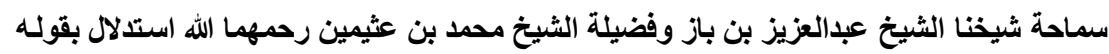
تعالى : \} وتعاونوا على البر والتقوى ولا تعاونوا على الإثم والعدوان واتقوا الله إن الله شديد

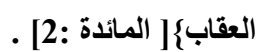

وذهب سماحة شيخنا الثيخ عبد الله بن محمد بن حميد رئيس مجلس القضاء الأعلى سابقاً رحمه الله

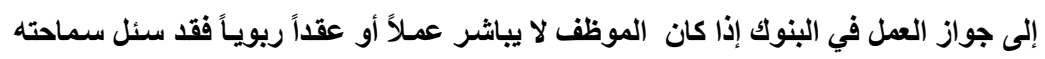

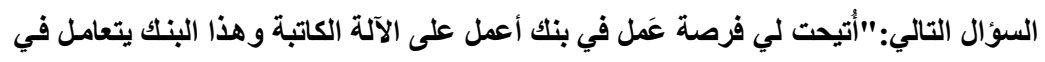

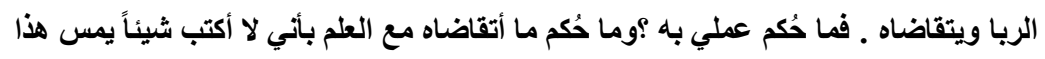

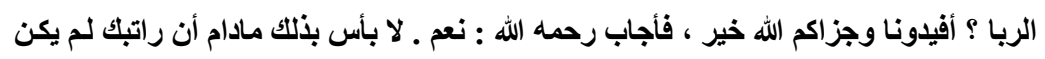

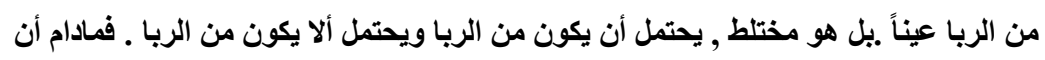

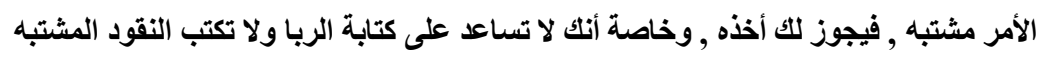

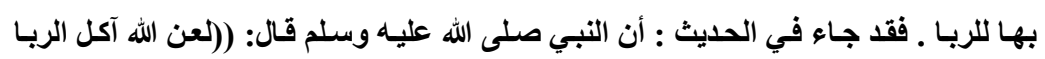

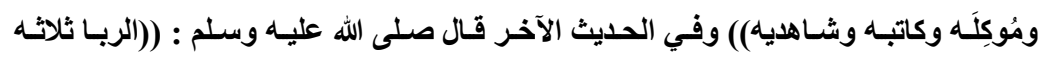

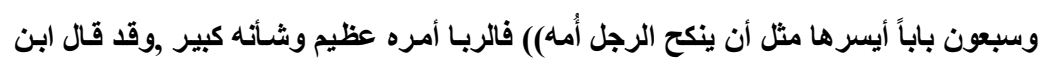

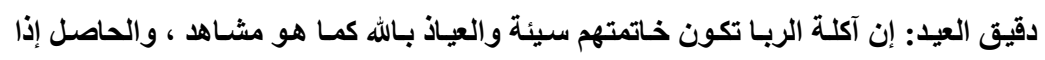

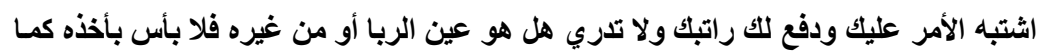

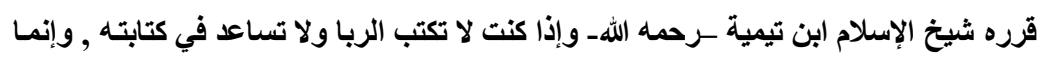

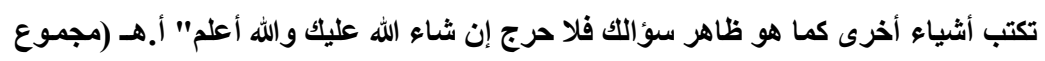

فتاو اه ص 188-187).

وهذا القول هو الصواب والاليل على ذلك ما روى عبدالله بن مسعود رضي الله عنه أن رسول الله

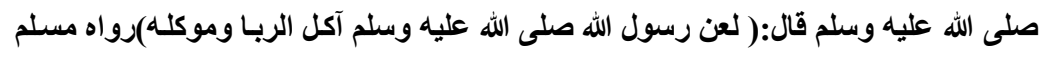

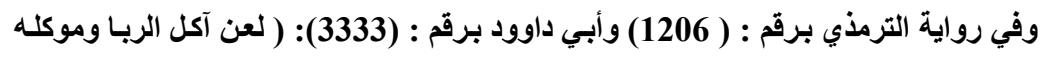

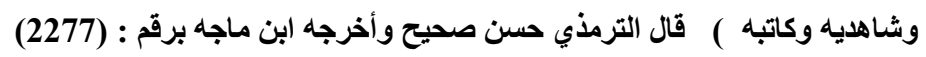

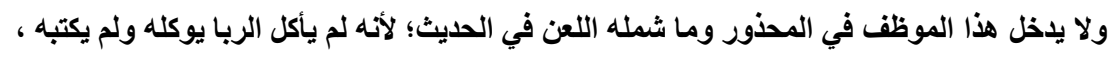

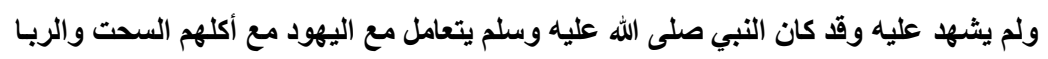


و الدكتور يوسف|القرضاوي(1). أدلة القول الأول : - أل

الـليل الأول : : ج وتعـاونوا على البر والتقوى ولا تعساونوا على

[2: الإثم والعدوان واتقوا الله إن الله شديد العقاب\{ [ المائدة *وجه الدلالة : التعاون مع البنوك كله تعاون على الإثم والعدوان،

فلا يجوز. (2) نوقش : الآيـة الكريمـة تنص على أن النهي إنمـا هو عن التعاون على الإثم والعدوان - أي في نفس العمل المحرم - مثل الذي يقدم الخمر لشاربيه أو يعين على صنعه ، أمـا من يتعامل مـع شـارب الخمر

كما في الحديث الصحيح عن عائشة رضي الله عنها أن رسول الله صلى الله عليه وسلم اشترى

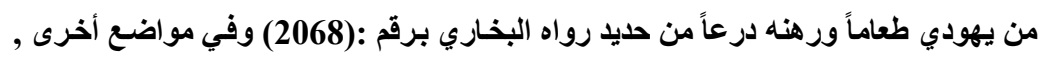
(1603/152 ) ومسلم برقا

وأما الآية الكريمة فهي تنص على أن النهي إنما هو عن التعاون على الإثم والعدوان - أي في نفس التس

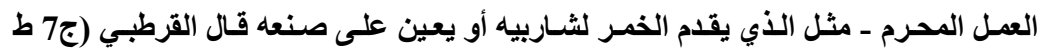

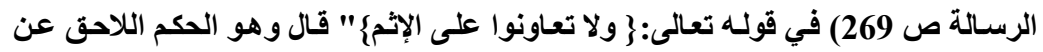

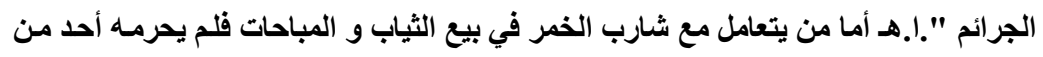
المسلمين مثل الموظف الذي يعمل في إدارة لا علاقة لها بالمحرمات والله أعلم ، أملاه الفقير

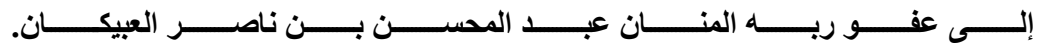
http://al3bikan.com/article/110-

http://www.qaradawi.net/new انظر موقع الثيخ يوسف القرضاوي. الله

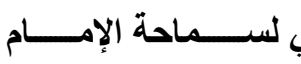

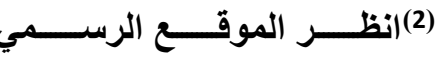

\section{htt://www.binbaz.org}


في بيع الثياب و المباحات فلم يحرمه أحل من المسلمين مثل الموظف

الذي يعمل في إدارة لا علاقة لها بالمحرمات والله أعلم. الاليل الثاني: عن جابر قال: ((لعن رسول الله صلى الله عليه وسلم

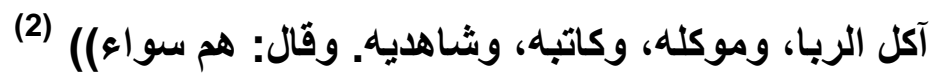
وجه الدلالة : العمل في البنوك ولو بأعمال غير بويـة محرم لأنها

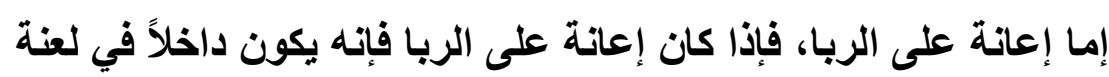

المعين وإن لم يكن إعانة فهو رضا بهذا العمل، وإقرارّ له. نوقش : ولا يدخل هذا الموظف في المدذور ولم يثمله اللعن في

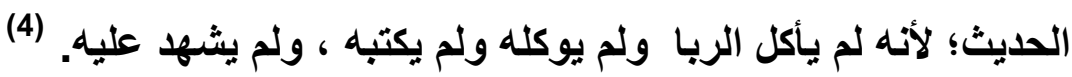

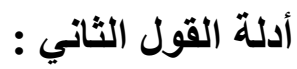

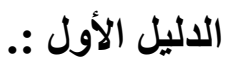

2- عن عائشة رضي الله عنها : (( أن النبي م اشترى طعامـا من

يهودي إلى أجل ، ورهنه درعاً من حديد)). (1)

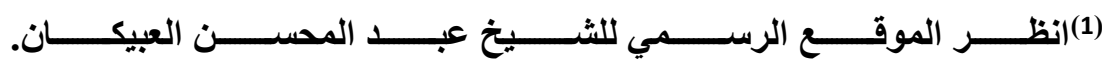

http://al3bikan.com-

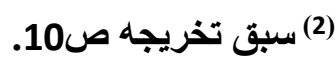

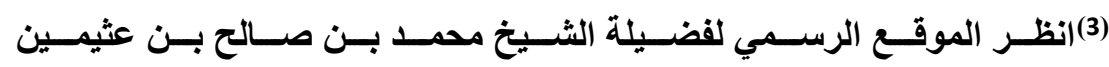
http://binothaimeen.ne/ http://binothaimeen.net/content/4369 (4) انظر الموقع الرسمي للثيخ عبد المحسن العبيكان. http://al3bikan.com 
(1) أخرجه البخاري ، كتاب البيوع ، باب شراء النبيم بالنسيئة ، 56/3 ، حديث رقم (2068) ، وأخرجه مسلم ، باب الرهن وجوازه في الحضر كالسفر، 1226/3

$$
\text { ، حديث رقم (1603 ) ، }
$$


وجـه الالالـة : وقد كـان النبـي صـلى الله عليـه وســلم يتعامـل مـع

اليهود مع أكلهم السحت والربا . (1)

الاليل الثاني : عن أبي هريرة رضي الله عنه قال : قال رسول م : (أيأتين على النـاس زمسان لا يبقى منهم أحد إلا أكل الربـا ، فمن لـم

يأكل أصابه من غباره)). (2)

وجه الالالة : أن وضع الربـا لـم يعد متعلقا بموظف في بنك ، أو

كاتب في شركة ، فهو يـخل في تركيب نظامنـا الاقتصـادي وجهازنـا

المالي كله فأصبح البلاء به عاما كما تتبأ نبينام. (3)

الاليل الثالث : أن منع المسلمين مطلقا من العمل في البنوك يفضي إلى سيطرة غير المسلمين من يهود وغيرهم على أعمـال البنولك ومـا

(4) شاكلها .

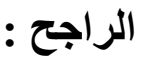

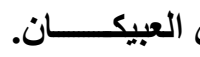

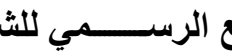

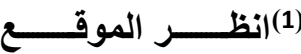

http://al3bikan.com

(2) أخرجه (بن ماجة ، كتاب التجارات ، باب التظليظ في الربا ، 765/2 ، حديث رقم ( 2278 ) ، وأبو داود ، كتاب البيوع ، باب اجتناب الثبهات ، 243/3 ، حديث رقم ( 3331 ) ، وضـفه الألباني في ضعيف الجـامع الصغيروزيادته 702/1 وفي تحقيقه لمشكاة المصابيح 857/2. http://www.qaradawi.net/new (3) موقع الثيخ يوسف القرضاوي. (4) (المصدر السابق. 
لاشتك أن الأحوط للمسلم في دينها اجتــاب كافة صور العمل في المصارف الربوية ، ولكن مـا ترجح عندي والله أعلم هو القول الثاني

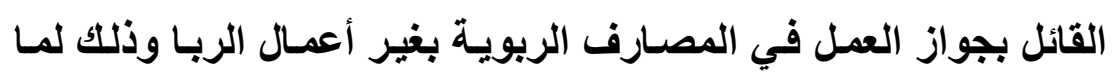

$$
\text { يلي : }
$$

1- قوة أدلتهم وسلامتها من المناقثة.

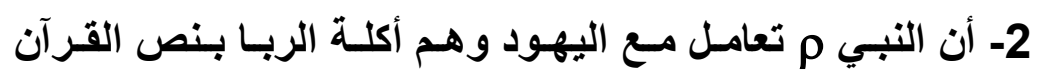

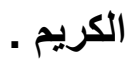

3- من المعلوم شرعا أن الحاجة تنزل منزلة الضرورة ، والحاجة

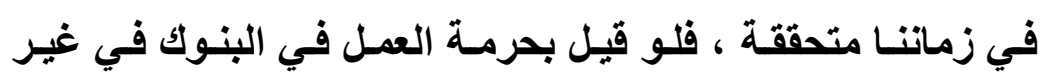

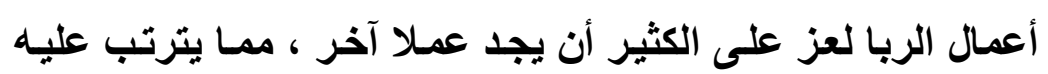

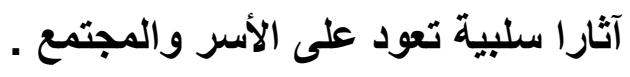




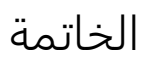

إن الحمد الله نحمده ونستعينه ، ونعوذ بـالله من شـرور أنفسـنا ،

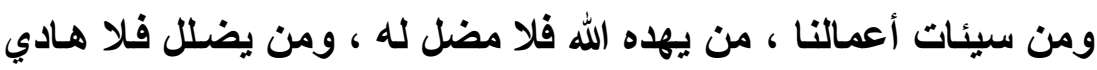

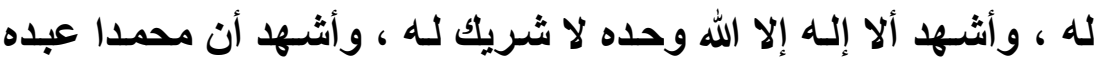

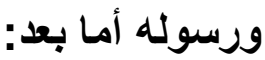

فإنه بنهايـة هذا البحث في مسـألة : ( حكم العمل في المصـارف الريوية ) يمكن أن أجمل ما توصلت إليه من نتائج فيما يلي: 1- أهمية الكسب الحلال وحث الثـارع العظيم على ذلكت ، وتحريم الربا والتحذير منه ، وترتيب الوعيد عليه في الانيا والآخرة .

2- اتفاق الفقهاء على حرمة العمل في المصارف الربويـة بأعمال

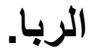

3- تحريم الإجـارة على حمل الخمر وهو الراجح من قولي أهل

4- جواز العمل في البنوك بغير أعمال الربا .

5- وجوب سعي الأمة إلى العمل على تطهير تعاملاتها البنكية من

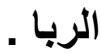




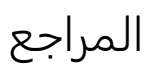

1- انظر تفسير الكريم الـرحمن في تيسير كـلام المنــان ، ج1 ،ص 242 ، ط1421 هـ ، مؤسسة الرسالة ، بيروت

2- بائع الصنائع في ترتيب الثرائع، علاء الدين أبو بكر بن مسعود بن أحمد الكاساني، ط2، 1406هـ، دار الكتب العلمية.

3- الهايـة في شرح بلاية المبتدي، علي بن أبي بكر بن عبد الجليل المرغيناني، دار إحياء التراث العربي، بيروت.

4- المبسـوط، محمــ بـن أحمــ السرخسـي، 1414هـ، دار المعرفـة،

$$
\text { بيزوث. }
$$

5- المغني، أبـو محمد موفق الـدين عبد الله بـن احمـ بـن محمــ بـن قدامة، 1388هـ، مكتبة القاهرة.

6- المسند الصحيح المختصر بنقل العدل عن العدل إلى رسول الله م، مسلم بـن الحجـاج القشـيري النيسـابوري، دار إحيـاء التـراث العربـي،

$$
\text { بيروت، تحقيق محمد فؤاد عبدالباقي. }
$$

7- الجـامع المسـنـا الصــيح، محمــد بـن إســـاعيل البخـاري، ط1، 1422 هـ، دار طوق النجاة، تحقيق محمد زهير بن ناصر الناصر. 8- صحيح وضعيف سنن ابن ماجة، محمد ناصر الدين الألباني، برنـامج منظومـة التحقيقات الحديثية من إنتاج مركز نور الإسـلام لأبحاث

$$
\text { القرآن والسنة بالإسكندرية }
$$

9- سـنن أبـي داود، أبـو داود ســليمان بـن الأشــثث بـن إســاق السجستاني، دار الفكر، تحقيق محمد محيي الدين عبد الحميا.

10- مشكاة المصابيح ، محمد بن عبد الله الخطيب التبريزي ، ط3 ، المكتب الإسلامي بيروت ، تحقيق محمد ناصر الدين الألباني. 
11- سنن ابن ماجة ، ابن ماجة أبو عبد الله محمد بن يزيد القزويني ، دار إحياء الكتب العربية ، تحقيق محمد فؤاد عبد الباقي.

12- ضعيف الجامع الصغير وزيادته ، أبو عبد الرحمن محمد ناصر

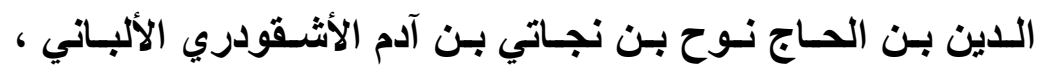

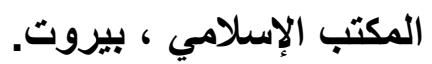

13- سنن الترمذي، محمد بن عيسى بن سورة بن موسى الضحاك

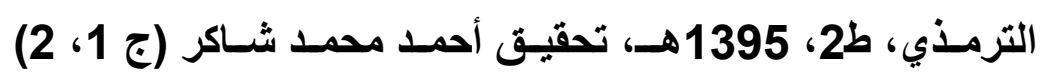

$$
\text { ومحمد فؤاد عبد الباقي ج3. }
$$

14- إرواء الظليل في تخريج أحاديث منـار السبيل ، محمد ناصر الاين الألباني ، ط2 ، المكتب الإسلامي بيروت .

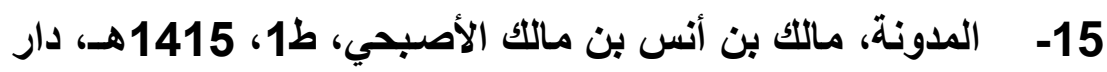

$$
\text { الكتب العلمية. }
$$

16- التتبيه في الفقه الثافعي، أبو إسحاق إبراهيم بن علي بن يوسف الثيرازي، عالم الكتب.

17- مواهب الجليل في شرح مختصر خليل، شمس الدين محمد بن محمد بن عبد الرحمن الطرابلسي المغريـي المعروف بالحطـاب الرعيني، ط3، 1412هـ، دار الفكر.

18- مغني المحتاج إلى معرفة معاني ألفاظ المنهاج، شمس الدين محمد بن أحمد الخطيب الثربيني، ط1، 1415 14ه، دار الكتب العلمية.

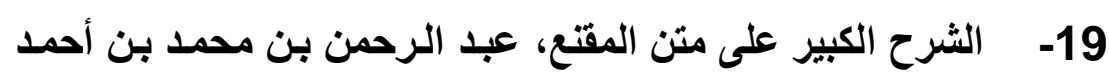
بن قدامة، دار الكتاب العربي للنشر والتوزيع.

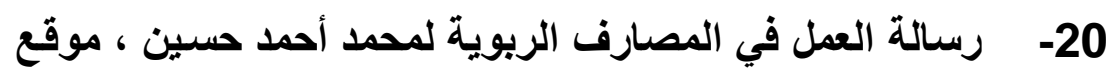

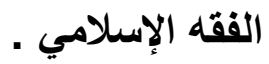


21- الاستيعاب في معرفة الأصحاب، تأليف: يوسف بن عبد الله بن

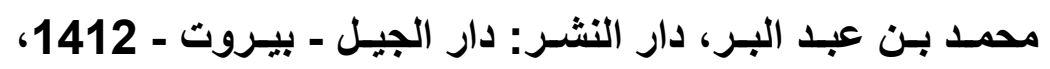
الطبعة: الأولى، تحقيق: علي محمد البجاوي.

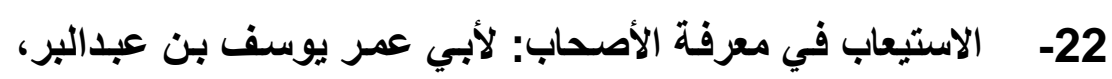

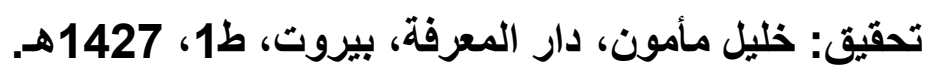

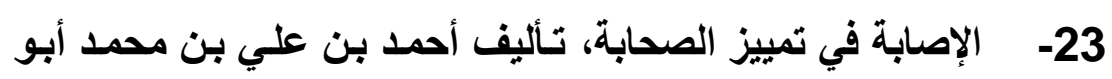

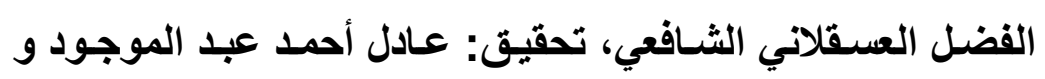

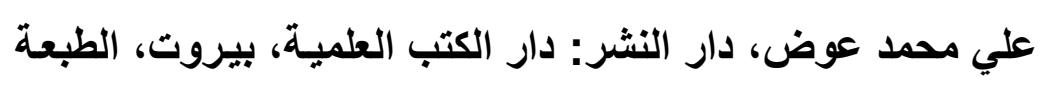

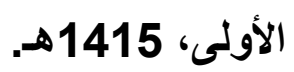

24- الإصابة في تمييز الصحابة، تأليف: أحمد بن علي بن حجر أبو

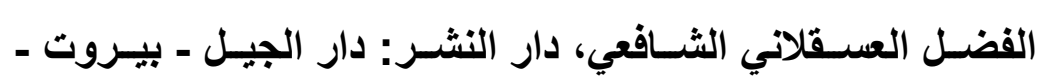
1412 - 1992، الطبعة: الأولى، تحقيق: علي محمد البجاوي.

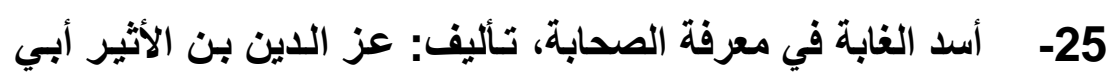

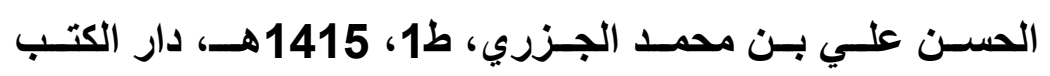
العلمية، تحقيق: علي محمد معوض ـ عادل أحمد عبد الموجود. 26- الأعلام، لخير الدين بن محمود الزركلي، دار العلم للملايين، بيروت، سنة 1980م.

27- الأعلام، لخير الدين بن محمود الزركلي، ط 15، 2002م، دار

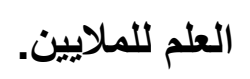

28- تهذيب التهذيب، تـأليف: أحمد بن علـي بن حجر أبو الفضل

العـقلاني الثـافعي، دار النثـر: دار الفكر - بيـروت - 1404 - 1984

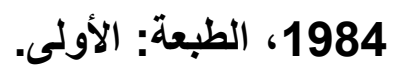


29- الثقـات، تـأليف: محمـد بـن حبـان بـن أحمـد أبـو حساتم التميمسي البستي، دار النشر: دار الفكر - 1395 - 1975، الطبعة: الأولى، تحقيق: السيد شرف الدين أحمد. 30- الطبقات الكبرى، تـأليف: محمد بـن سـعد بن منيع أبو عبدالله البصري الزهري، دار النشر: دار صادر - بيروت -.

31- مشـاهير علمـاء نجد وغيرهم، عبد الرحمن بن عبد اللطيف آل الثيخ، دار اليمامة للبحث والترجمة والنشر، الريـاض، ط الثانية،

32- المعجم الجـامع في تراجم العلمـاء وطلبة العلم المعاصرين، اعداد وتقديم / أعضاء ملتقى أهل الحديث.

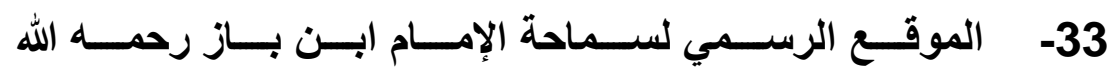
htt://www.binbaz.org.sa/fatawa/4035

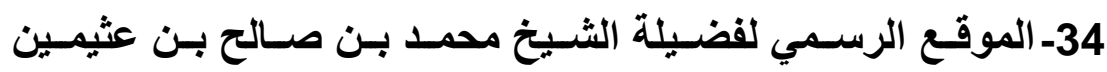
http://binothaimeen.net/content/3150 http://binothaimeen.net/content/4369

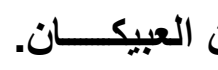

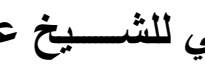

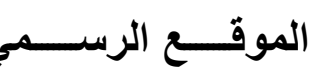
$-35$ http://al3bikan.com/article/110-

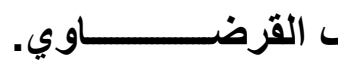
بخ ع الث

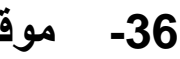
http://www.qaradawi.net/new/Articles-8639

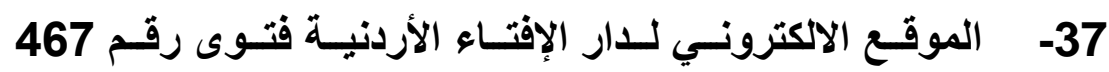
http://www.aliftaa.jo/question.aspx

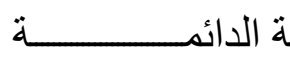
للجن

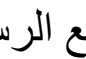
38-الموق http://www.alifta.net/fatawa/fatawaDetails.aspx?View=Page $\&$ PageID $=5483 \&$ PageNo $=1 \&$ BookID $=3$ 